\title{
Characterization of Plasmid-Mediated Quinolone Resistance and Serogroup Distributions of Uropathogenic Escherichia coli among Iranian Kidney Transplant Patients
}

\author{
Amin Sadeghi $\mathbb{D}^{D}$, Mehrdad Halaji $\mathbb{D}^{D}$, Amirhossein Fayyazi $\mathbb{D}^{\circ}$, and Seyed Asghar Havaei \\ Department of Microbiology, School of Medicine, Isfahan University of Medical Sciences, Isfahan, Iran \\ Correspondence should be addressed to Seyed Asghar Havaei; havaei@med.mui.ac.ir
}

Received 26 June 2020; Revised 12 August 2020; Accepted 22 October 2020; Published 28 October 2020

Academic Editor: Yun Peng Chao

Copyright (C) 2020 Amin Sadeghi et al. This is an open access article distributed under the Creative Commons Attribution License, which permits unrestricted use, distribution, and reproduction in any medium, provided the original work is properly cited.

\begin{abstract}
Introduction. Urinary tract infection (UTI) is one of the most frequent infections in kidney transplant patients (KTPs). This infection is mainly caused by uropathogenic Escherichia coli (UPEC). Plasmid-mediated quinolone resistance (PMQR) was also increasingly identified in UPEC. This study proposed to investigate the frequency of quinolone-resistance plasmid genes and the O-antigen serogroup among UPEC isolated from KTPs and non-KTP with UTI. Methods. Totally, 114 UPEC isolates from 49 KTPs and 65 non-KTPs patients diagnosed with an UPEC-associated UTI were obtained from June 2019 to December 2019 at three laboratory centers in Isfahan, Iran. The isolates were confirmed through phenotypic and genotypic methods. Moreover, the antimicrobial susceptibility test to nalidixic acid, ciprofloxacin, norfloxacin, and ofloxacin was performed using a disk diffusion method. The presence of the $q n r$ gene as well as the serogroup distribution was identified using the PCR method. Result. According to data, the distribution of O1, O2, O4, O16, and O25 serogroups were 3.5\%, 2.6, 3.5, 3.5, and 20.2\%, respectively. Antibiotic susceptibility pattern revealed that the highest and lowest resistance rates were to nalidixic acid (69.3\%) and norfloxacin (43.9\%), respectively. Also, the frequency of $q n r S$ and $q n r B$ genes were $33.3 \%$ and $15.8 \%$, respectively, while none of the isolates was found to be positive for the $q n r A$ gene. There was no significant association between the presence of $q n r$ genes and higher antibiotic resistance. Conclusion. This study recognized that the qnrS gene, O25 serotype, and resistance to nalidixic acid had the highest frequencies in UPEC strains isolated from UTI patients.
\end{abstract}

\section{Introduction}

Urinary tract infection (UTI) has been recognized as the second-ranking infectious disease worldwide that is, and UTIs are known as a serious global concern in public health care systems [1]. Moreover, UTIs are one of the most frequent infections in kidney transplant patients (KTPs) [2]. The effects of UTI on kidney transplantation (KTx) have been well reported in previous studies [3]. UTI occurs in $60 \%$ of KTPs patients during the first year posttransplant [4]. Almost 70\% of these UTIs are caused by gram-negative bacteria [3]. Escherichia coli (E. coli) strains, in particular, uropathogenic E. coli (UPEC) pathotype, are known as the most frequent gram-negative bacteria causing UTIs after KTx $[1,5]$. On the other hand, antibiotic therapy of UTI has become problematic due to misuse of antibiotics which can in turn give rise to the emergence of resistant strains [6]. Quinolones are a group of artificial antimicrobial agents with a broad antibacterial activity, frequently used as a treatment in patients with UTI. These groups have been divided into four generations based on their antimicrobial activity; nalidixic acid, ciprofloxacin, and levofloxacin that are members of the first, second, and third generations, respectively $[6,7]$. Quinolones, in particular, ciprofloxacin, is one of the agents frequently utilized for treatment of UTIs. Moreover, it is considered as an effective treatment in prevention of UTI in KTPs [8]. DNA gyrase (topoisomerase II) and topoisomerase IV are named as the primary and secondary targets for quinolones [6]. The extent of quinolone-resistant genes in gram-negative bacteria like UPEC is a big concern for KTPs [1]. Quinolone resistance ( $q n r)$ is caused by several mechanisms which plasmid-mediated quinolone resistance 
(PMQR) is one of the most important of them. Moreover, PMQR is approved by the $q n r$ genes. The qnr genes contain $q n r A, q n r B, q n r C$, and $q n r S[6,9]$. Qnr proteins are protecting target enzymes DNA gyrase and topoisomerase IV of quinolone inhibition [7]. Further, PMQR provides only a low level of quinolone resistance; however, PMQR genes may facilitate the selection of higher-level resistance in the presence of quinolones and lead to treatment breakdown [7]. The E. coli strains are commonly classified on the basis of serological typing of their $\mathrm{H}$ (flagellar), $\mathrm{O}$ (lipopolysaccharide), and in some cases, and $\mathrm{K}$ (capsular) surface antigens [10]. To date, although more than 174 different serogroups have been reported for $E$. coli, some O-antigen types usually expressed in UPEC clones, including $01,02,04,06,07$, $\mathrm{O} 8, \mathrm{O} 16, \mathrm{O} 18, \mathrm{O} 25$, and $\mathrm{O} 75$ [11]. To the best of our knowledge, few studies have investigated quinolone resistance and O-serogroups in UPEC strains among KTPs. Therefore, this study was designed to determine the prevalence of quinolone resistance and $\mathrm{O}$-serogroups $(\mathrm{O} 1, \mathrm{O} 2, \mathrm{O} 4, \mathrm{O} 16$, and $\mathrm{O} 25)$ in UPEC strains isolated from Iranian KTPs and non-KTPs with UTIs.

\section{Material and Method}

2.1. Study Design and Bacterial Isolation. This cross-sectional study conducted from June 2019 to December 2019, in three laboratory centers and two nephrology private clinics in Isfahan, Iran. 65 nonrepetitive UPEC isolates obtained from non-KTP with UTIs, and 49 nonrepetitive UPEC isolates obtained from KTPs with UTIs. This study was evaluated and approved by the Ethics Committee of Isfahan University of Medical Sciences (IR.MUI.MED.REC.1398.196). The UPEC isolates were confirmed as $E$. coli by gram staining and the standard biochemical tests in previously described [12]. The confirmed isolates were stored at $-80^{\circ} \mathrm{C}$ in brain heart infusion broth containing $20 \%$ glycerol.

2.2. Quinolone Susceptibility Testing. The antibiotic susceptibility pattern was determined based on the disk diffusion method on Mueller-Hinton agar (HiMedia Co., India) according to the Clinical and Laboratory Standards Institute (CLSI) [13] recommendation for nalidixic acid, ciprofloxacin, norfloxacin, and ofloxacin (BD BBL ${ }^{\mathrm{TM}}$ Sensi-Disc $\left.{ }^{\mathrm{TM}}\right)$.

2.3. Detection of qnr Encoding Genes. Genomic DNA was extracted from fresh colonies as described previously [14]. PCR was performed to detect the presence of $q n r A$, qnrB, and $q n r S$ genes using the specific primers [15]. The conditions for PCR amplification were initial denaturation at $94^{\circ} \mathrm{C}$ for 5 minutes, followed by 30 cycles of denaturation at $94^{\circ} \mathrm{C}$ for 30 seconds, primer annealing at $55^{\circ} \mathrm{C}$ for $q n r A$ and $q n r B$ and $58^{\circ} \mathrm{C}$ for $q n r S$ for 30 seconds, extension at $72^{\circ} \mathrm{C}$ for 30 seconds, and a final extension at $72^{\circ} \mathrm{C}$ for 5 minutes. Amplification products were analyzed using 1.5\% agarose gel with KBC power load dye (CinnaGen Co. Iran). Positive results were confirmed by direct sequencing of the PCR products.

2.4. Characterization of the Lipopolysaccharide O Antigens. $\mathrm{PCR}$ was performed to detect the presence of $\mathrm{O} 1, \mathrm{O} 2, \mathrm{O} 4$,
O16, and O25 genes using the specific primers [11]. The conditions for PCR amplification were initial denaturation at $94^{\circ} \mathrm{C}$ for 5 minutes, followed by 30 cycles of denaturation at $94^{\circ} \mathrm{C}$ for 30 seconds, primer annealing at $55^{\circ} \mathrm{C}$ for $\mathrm{O} 1$ and $58^{\circ} \mathrm{C}$ for $\mathrm{O} 2$ and $\mathrm{O} 25$ and $56^{\circ} \mathrm{C}$ for $\mathrm{O} 4$ and $\mathrm{O} 16$ for 30 seconds, extension at $72^{\circ} \mathrm{C}$ for 30 seconds, and a final extension at $72^{\circ} \mathrm{C}$ for 5 minutes. Amplification products were analyzed using $1.5 \%$ agarose gel with $\mathrm{KBC}$ power load dye (CinnaGen Co. Iran).

The statistical analysis was done using SPSS software version 16.0 (IBM Corp., USA). For this study, Fisher's test and the nonparametric chi-square test were performed, and $P$ value $<0.05$ was considered statistically significant.

\section{Results}

During the period of study, in total, 114 confirmed UPEC was isolated, including $43 \%(49 / 114) \quad \mathrm{KTP}$ and $57 \%$ (65/114) control group. Furthermore, among KTP, 69.4\% (34/49) and $30.6 \%(15 / 49)$ isolates were female and male patients, respectively, while among non-KTP, 69.2\% (45/65) and $30.8 \%$ (20/65) isolates were obtained from female and male, respectively. The range age of the study group was from 10 to 80 years. The results of the antibacterial susceptibility test revealed that most isolates were resistant to nalidixic acid $69.3 \%$ (79/114), while the least resistance was demonstrated against norfloxacin 43.9\% (50/114). The total distribution of the antibacterial susceptibility test is shown in Table 1. UPEC strain isolated from KTP was highly resistant to nalidixic acid $75.5 \%$ (37/49) while the least resistance was demonstrated against ofloxacin 51\% (25/49) (Table 1). The antibiotic susceptibility pattern on the control group revealed that the highest and lowest resistance rates were against nalidixic acid $64.6 \%$ (42/65) and norfloxacin $35.4 \%$ $(23 / 65)$, respectively (Table 1$)$. Statically analysis showed that the resistance rate against norfloxacin was significantly higher among KTP than non-KTP (Table 1).

PCR amplification of the three genes $(q n r A, q n r B$ and $q n r S)$ showed that $33.3 \%(38 / 114)$ and $15.8 \%(18 / 114)$ of the isolates were positive for $q n r S$ and $q n r B$ genes, respectively, while none of the isolates was found to be positive for the qnrA gene (Table 2). In addition, 3.5\% (4/114) of the isolates were found positive for both genes. There was no significant relationship between $q n r$ genes and higher quinolone resistance in KTP and control group. However, the $q n r S$ gene was found to be relatively higher than the $q n r B$ gene among quinolone resistance isolates (Table 2). Accordingly, the qnr genes are most likely to happen in nalidixic acid resistant rather than fluoroquinolone-resistant isolates. The total distribution of $q n r$ genes among quinolone resistance KTP and non-KTP is presented in Tables 3 and 4. According to our finding, the high distribution of serogroups was $\mathrm{O} 25$ $(20.2 \%, 23 / 114)$, while the O2 serogroup $(2.6 \%, 3 / 114)$ was the lowest serogroups among UPEC isolates (Table 2). The total distribution of O-serogroups is summarized in Table 2. Overall, the $O 25$ serogroup $(60.9 \%, 14 / 23)$ had the highest distributions of serogroups while $\mathrm{O} 2, \mathrm{O} 4$, and $\mathrm{O} 16$ genes were not found in KTP (Table 2). 
TABLE 1: Antimicrobial susceptibility pattern of UPEC isolates among KTP and control group.

\begin{tabular}{lcccc}
\hline Antibiotic & Total & $\begin{array}{c}\text { KTP (49) } \\
\text { N (\%) }\end{array}$ & $\begin{array}{c}\text { Control group (65) } \\
N(\%)\end{array}$ & P value \\
\hline Nalidixic acid & 79 & $37(75.5)$ & $42(64.6)$ & 0.21 \\
Ciprofloxacin & 52 & $27(55.1)$ & $25(38.5)$ & 0.07 \\
Ofloxacin & 57 & $25(51)$ & $32(49.2)$ & 0.85 \\
Norfloxacin & 50 & $27(55.1)$ & $23(35.4)$ & $\mathbf{0 . 0 3}$ \\
\hline
\end{tabular}

TABLE 2: Distribution of qnr genes and O-serogroups among KTP and control group.

\begin{tabular}{lcccc}
\hline Genes & Total & $\begin{array}{c}\text { KTP (49) } \\
N(\%)\end{array}$ & $\begin{array}{c}\text { Control group (65) } \\
N(\%)\end{array}$ & $P$ value \\
\hline qnrB & $18(15.8)$ & $6(12.2)$ & $12(18.5)$ & 0.36 \\
qnrS & $38(33.3)$ & $15(30.6)$ & $23(35.4)$ & 0.59 \\
O1 & $4(3.5)$ & $4(8.2)$ & $0(0)$ & $\mathbf{0 . 0 1}$ \\
O2 & $3(2.6)$ & $0(0)$ & $3(4.6)$ & 0.12 \\
O4 & $4(3.5)$ & $0(0)$ & $4(6.2)$ & 0.07 \\
O16 & $4(3.5)$ & $0(0)$ & $4(6.2)$ & 0.07 \\
O25 & $23(20.2)$ & $14(28.6)$ & $9(13.8)$ & $\mathbf{0 . 0 5}$ \\
\hline
\end{tabular}

Of the studied O-serogroups, $\mathrm{O} 1$ and $\mathrm{O} 25$ genes were significantly higher among KTP than the control group (Table 2). All serogroups showed the highest resistance to ciprofloxacin, norfloxacin, and ofloxacin in KTP and nalidixic acid and norfloxacin in the control group (Tables 5 and 6). The results showed the significant resistance rate of ciprofloxacin and norfloxacin between the O25 serogroup in the control group (Table 6). According to future investigation, among 18 qnrB-carrying strains, 8,1 , and 1 isolates belonged to the $\mathrm{O} 25, \mathrm{O} 1$, and $\mathrm{O} 4$ serogroup, respectively. In addition, among 38 qnrS-carrying strains, 8 and 1 isolates belonged to the $\mathrm{O} 25$ and $\mathrm{O} 4$ serogroup, respectively.

\section{Discussion}

UTI is the most common disease among KTPs [16, 17], and the main cause of UTI is UPEC [18]. Furthermore, quinolones are the most common antibiotic used to treat UTI. Nowadays, fluoroquinolone resistance producing UPEC has increased worldwide [19]. In the present study, among all UPEC isolates, the highest and lowest resistance were to nalidixic acid (54.9\%) and norfloxacin (43.8\%), respectively. Moreover, the antibiotic susceptibility pattern in KTPs and non-KTPs revealed that nalidixic acid had the most antibiotic resistance with $75.5 \%$ (37/49) and $64.6 \%(42 / 65)$ rate, respectively. Therefore, it seems that we should be more cautious about using nalidixic acid and other quinolones with the aim of UTI treatment in our region. In a study conducted on KTPs, Siliano et al. (2010) reported a $31.66 \%, 28.99 \%$, and $28.99 \%$ resistance rate of nalidixic acid, norfloxacin, and ciprofloxacin, respectively [20]. Mohammadzadeh et al. (2019) investigated antibiotic susceptibility of UPEC isolates from KTPs. Their results showed that the resistance rate of ciprofloxacin and norfloxacin was $34.78 \%$ and $4.34 \%$, respec- tively [21]. This finding was not in agreement with our finding.

Additionally, in a study conducted on KTPs by Espinar et al. (2015), among ESBL-positive UPEC isolates, 48.5\% and $36.4 \%$ of isolates were resistant to ciprofloxacin and norfloxacin [22]. Moreover, Kashef Nejad et al. (2017) in a study on UPEC isolated from KTPs reported that $71.92 \%$ of ESBLproducing isolates had resistance toward ciprofloxacin [4]. In a meta-analysis study conducted by Moghaddam et al., among the UPEC strain isolated from KTPs, the resistance rate of quinolones agents to nalidixic acid and ciprofloxacin was reported to be $68.4 \%$ and $61 \%$, respectively [23]. These results were in consistent with the results of our study. Furthermore, a study carried out by Shenagari et al. (2018) revealed that among 223 UPEC isolates, nalidixic acid (61.9\%) and norfloxacin (45.3\%) were the highest antibiotic resistance among quinolone agents [24]. Similarly, in southwest of Iran, Farajzadeh Sheikh et al. found that $65.3 \%$ of UPEC isolates were resistant to nalidixic acid [25]. The results of these studies performed across Iran were close to our findings. Malekzadegan et al. (2019) showed that the highest resistance rates were to nalidixic acid (71.9\%) among 121 UPEC in a tertiary care hospital in the south of Iran [26]. Our studies showed a lower percentage of antibiotic resistance than that of hospital studies. This indicates that inpatients were more exposed to high antibiotic selective pressure or bacterial crosstransmission. This could be due to the reckless and inappropriate use of drugs. Furthermore, several findings suggested that the source of quinolones resistance and spread of resistance genes may be explained by animals-to-human-transmission routes, such as poultry and meat products, which can be in turn due to inappropriate use of antibiotics in the animal industry. Based on the molecular result, $45.6 \%(52 / 114)$ of the isolates contained $q n r$ genes. The most prevalent PMQR genes were qnrS 33.3\% (38/224) and $q n r B 15.8 \%(18 / 114)$, while the $q n r A$ genes were not found in this study. According to the literature review, the $q n r S$ gene seems to play a significant role in quinolone resistance than $q \eta r A$ and $q \eta r B$, which is consistent with our results among both KTPs and non-KTPs. Tarchouna et al. (2015) reported a frequency of $32 \%$ for the $q n r$ genes that the most frequent of them was $q n r B(12.5 \%)$, followed by $5.3 \%$ for qnrA, and 3.5\% for qnrS [27]. In multicenter study conducted in the west of Iran by Valadbeigi et al. (2020), results indicated that the frequency of $q n r B$ and $q n r S$ genes was $47.5 \%$ and $2.5 \%$, respectively [28]. The reason for this difference might be due to the hospital samples examined in these studies. Abbasi et al. (2018) further found that the prevalence of $q n r B$ and $q n r S$ genes was $25 \%$, and $36 \%$, respectively, in Tehran [1]. In agreement with our studies, Röderova et al. (2017) and Rezazadeh et al. (2016) asserted that the $q n r A$ genes were not found among the isolates [29, $30]$. Systematic O-serogrouping of $E$. coli began in the early 1930s, and it became an important tool for the classification of E. coli strains in clinical settings [31]. Much evidence of experimental studies is showing a close connection among certain serogroups and certain markers of pathogenicity in pathogens, such as UPEC $[32,33]$. Overall, O1, O2, O4, O16, and $\mathrm{O} 25$ were the detected O-serogroups among the 
TABLE 3: Distribution of $q n r$ genes among quinolone resistance in KTP.

\begin{tabular}{|c|c|c|c|c|c|c|c|}
\hline Antibiotic & Pattern & $\begin{array}{c}q n r S \text {-positive } \\
\text { no. }(\%)\end{array}$ & $\begin{array}{c}q n r S \text {-negative } \\
\text { no. }(\%)\end{array}$ & $P$ value & $\begin{array}{c}q n r B \text {-positive } \\
\text { no. }(\%)\end{array}$ & $\begin{array}{c}q n r B \text {-negative } \\
\text { no. }(\%)\end{array}$ & $P$ value \\
\hline \multirow{2}{*}{ Nalidixic acid } & $\mathrm{R}(n=37)$ & $10(27)$ & $27(73)$ & 0.47 & $4(10.8)$ & $33(89.2)$ & 0.59 \\
\hline & $\mathrm{S}(n=12)$ & $5(41.7)$ & $7(58.3)$ & & $2(16.7)$ & $10(83.3)$ & \\
\hline \multirow{2}{*}{ Ciprofloxacin } & $\mathrm{R}(n=27)$ & $9(33.3)$ & $18(66.7)$ & 0.64 & $3(11.1)$ & $24(88.9)$ & 0.78 \\
\hline & $\mathrm{S}(n=22)$ & $6(27.3)$ & $16(72.7)$ & & $3(13.6)$ & $19(86.4)$ & \\
\hline \multirow{2}{*}{ Ofloxacin } & $\mathrm{R}(n=25)$ & $9(36)$ & $16(64)$ & 0.40 & $2(8)$ & $23(92)$ & 0.35 \\
\hline & $\mathrm{S}(n=24)$ & $6(25)$ & $18(75)$ & & $4(16.7)$ & $20(83.3)$ & \\
\hline \multirow{2}{*}{ Norfloxacin } & $\mathrm{R}(n=27)$ & $9(33.3)$ & $18(66.7)$ & 0.64 & $3(11.1)$ & $24(88.9)$ & 0.78 \\
\hline & $S(n=22)$ & $6(27.3)$ & $16(72.7)$ & & $3(13.6)$ & $19(86.4)$ & \\
\hline
\end{tabular}

Abbreviations: R: resistant; S: susceptible.

TABLE 4: Distribution of $q n r$ genes about quinolone resistance in control-group.

\begin{tabular}{|c|c|c|c|c|c|c|c|}
\hline Antibiotic & Pattern & $\begin{array}{c}q n r S \text {-positive } \\
\text { no. }(\%)\end{array}$ & $\begin{array}{c}q n r S \text {-negative } \\
\text { no. }(\%)\end{array}$ & $P$ value & $\begin{array}{c}q n r B \text {-positive } \\
\text { no. }(\%)\end{array}$ & $\begin{array}{c}q n r B \text {-negative } \\
\text { no. }(\%)\end{array}$ & $P$ value \\
\hline \multirow{2}{*}{ Nalidixic acid } & $\mathrm{R}(n=42)$ & $12(28.6)$ & $30(71.4)$ & \multirow[t]{2}{*}{0.12} & $9(21.4)$ & 33 (78.6) & \multirow[t]{2}{*}{0.51} \\
\hline & $\mathrm{S}(n=23)$ & $11(47.8)$ & $12(52.2)$ & & $3(13)$ & $20(87)$ & \\
\hline \multirow{2}{*}{ Ciprofloxacin } & $\mathrm{R}(n=25)$ & $8(32)$ & $17(68)$ & \multirow[t]{2}{*}{0.65} & $6(24)$ & $19(76)$ & \multirow[t]{2}{*}{0.51} \\
\hline & $\mathrm{S}(n=40)$ & $15(37.5)$ & $25(62.5)$ & & $6(15)$ & $34(85)$ & \\
\hline \multirow{2}{*}{ Ofloxacin } & $\mathrm{R}(n=32)$ & $11(34.4)$ & $21(65.6)$ & \multirow[t]{2}{*}{0.86} & 7 (21.9) & $25(78.1)$ & \multirow[t]{2}{*}{0.48} \\
\hline & $\mathrm{S}(n=33)$ & $12(36.4)$ & $21(63.6)$ & & $5(15.2)$ & $28(84.8)$ & \\
\hline \multirow{2}{*}{ Norfloxacin } & $\mathrm{R}(n=23)$ & $7(30.4)$ & $16(69.6)$ & \multirow[t]{2}{*}{0.53} & $6(26.1)$ & $17(73.9)$ & \multirow[t]{2}{*}{0.31} \\
\hline & $S(n=42)$ & $16(38.1)$ & $26(61.9)$ & & $6(14.3)$ & $36(85.7)$ & \\
\hline
\end{tabular}

Abbreviations: R: resistant; S: susceptible.

TABLE 5: Antimicrobial resistance pattern in UPEC isolates based on serogroups in KTP.

\begin{tabular}{|c|c|c|c|c|c|c|c|}
\hline Antibiotic & Pattern & $\begin{array}{l}\text { O1-positive } \\
\text { no. }(\%)\end{array}$ & $\begin{array}{l}\text { O1-negative } \\
\text { no. }(\%)\end{array}$ & $P$ value & $\begin{array}{c}\text { O25-positive } \\
\text { no. }(\%)\end{array}$ & $\begin{array}{c}\text { O25-negative } \\
\text { no. }(\%)\end{array}$ & $P$ value \\
\hline \multirow{2}{*}{ Nalidixic acid } & $\mathrm{R}(n=37)$ & $4(10.8)$ & $33(89.2)$ & 0.23 & $9(24.3)$ & $28(75.7)$ & 0.28 \\
\hline & $S(n=12)$ & $0(0)$ & $12(100)$ & & $5(41.7)$ & $7(58.3)$ & \\
\hline \multirow{2}{*}{ Ciprofloxacin } & $\mathrm{R}(n=27)$ & $3(11.1)$ & $24(88.9)$ & 0.40 & 7 (25.9) & $20(74.1)$ & 0.65 \\
\hline & $\mathrm{S}(n=22)$ & $1(4.5)$ & $21(95.5)$ & & $7(31.8)$ & $15(68.2)$ & \\
\hline \multirow{2}{*}{ Ofloxacin } & $\mathrm{R}(n=25)$ & $2(8)$ & $23(92)$ & 0.96 & $7(28)$ & $18(72)$ & 0.92 \\
\hline & $\mathrm{S}(n=24)$ & $2(8.3)$ & $22(91.7)$ & & $7(29.2)$ & $17(70.8)$ & \\
\hline \multirow{2}{*}{ Norfloxacin } & $\mathrm{R}(n=27)$ & $3(11.1)$ & $24(88.9)$ & 0.40 & 7 (25.9) & $20(74.1)$ & 0.65 \\
\hline & $\mathrm{S}(n=22)$ & $1(4.5)$ & $21(95.5)$ & & $7(31.8)$ & $15(68.2)$ & \\
\hline
\end{tabular}

Abbreviations: R: resistant; S: susceptible.

UPEC isolates in this study. Moreover, in the current study, $33.3 \%(38 / 114)$ of the isolates detected O-Serogroups. O25, $20.2 \%$ (23/114), was the most commonly detected Oserogroups in UPEC strains of our study. Our results also indicated that there was several serogroups of $E$. coli in KTP patients with UTI. There were statistically significant differences between the presence of $O 25(P<0.05)$ and $O 1$ $(P<0.01)$ serogroups in KTPs in comparison with nonKTPs. Consistent with our result, in a study by Lau et al., on 43 UPEC strains isolated, the most prevalent serogroup was reported $\mathrm{O} 25$ with 21 cases (48.84\%) [34]. Noie Oskouie et al. (2019) reported that the gene of O25 (55.8\%) was the most commonly detected serogroups among UPEC [35]. In another study carried out by Basha et al. (2019) among KTPs, the frequency of $02,04,016$, and $\mathrm{O} 25$ was reported to be $7 \%, 4.2 \%, 2.8 \%$, and 5.6\%, respectively [5]. Furthermore, according to the results of Momtaz et al.'s study (2013), O25 (26.01\%), O16 (10.56\%), O4 (5.69\%), O1 (2.43\%), and O2 $(2.43 \%)$ were the most commonly detected serogroups among Iranian hospitalized patients [36]. Shokouhi Mostafavi et al. (2019) showed that $O 1$ (20\%) and $O 25$ (13.7\%) were the major O-serogroups among UPEC isolates in Iran [37]. According to the distribution of quinolone resistance in various $\mathrm{O}$ groups in non-KTPs, the isolates belonged to the $\mathrm{O} 25$ 


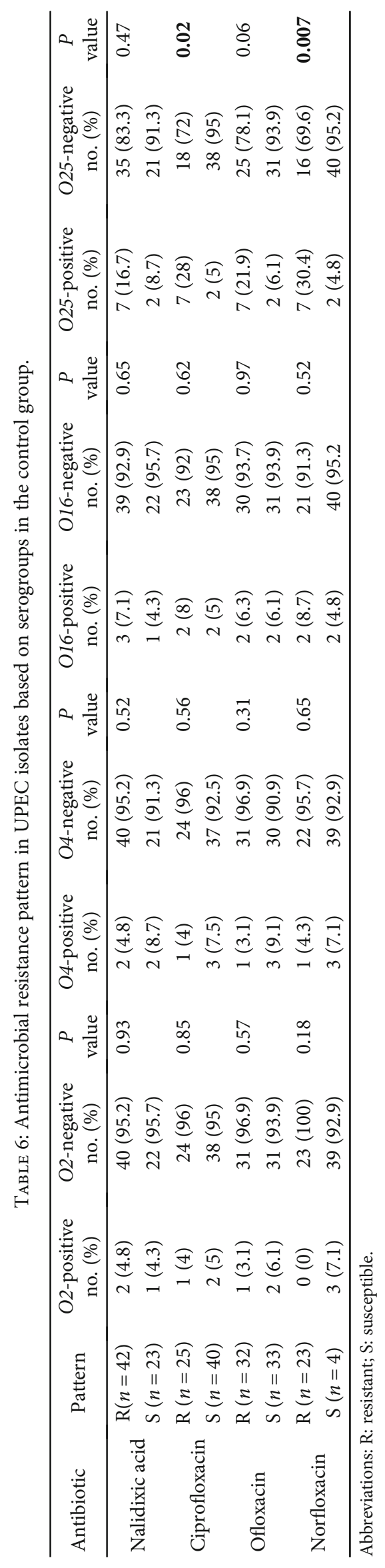


group showed the significant resistance rate to ciprofloxacin and norfloxacin than the other $\mathrm{O}$ groups. In general, the different distributions of O-serogroups among UPEC isolates can vary depending on the type of infection, region, or even different settings (hospital or community). Based on our results, qnrS gene, O25 serotype, and finally, resistance to nalidixic acid had the highest frequencies in UPEC strains isolated from UTI patients. We also recommend antibiotics taking only in severe conditions since quinolone resistance has been increased in UPEC strains.

\section{Data Availability}

The data that support the findings of this study are available from the corresponding author upon reasonable request.

\section{Ethical Approval}

The study protocol was approved by the Ethics Committee of Isfahan University of Medical Sciences (IR.MUI.MED.REC.1398.196); however, we did not have human participants. The study used bacteria isolated from clinical samples in the clinical microbiology laboratory.

\section{Conflicts of Interest}

The authors report no conflicts of interest in this work.

\section{Acknowledgments}

The authors would like to appreciate the Department of Microbiology of Isfahan University of Medical Sciences.

This study was funded by the Isfahan University of Medical Science (grant number 398312).

\section{References}

[1] H. Abbasi and R. Ranjbar, "The prevalence of qnr genes of A, B, S in Escherichia coli strains isolated from three major hospitals in Tehran, Iran," Central European Journal of Urology, vol. 71, pp. 129-133, 2018.

[2] J. Coussement, M. A. Argudín, A. Heinrichs et al., "Host and microbial factors in kidney transplant recipients with Escherichia coli acute pyelonephritis or asymptomatic bacteriuria: a prospective study using whole-genome sequencing," Nephrology, Dialysis, Transplantation, vol. 34, no. 5, pp. 878-885, 2019.

[3] P. Ramadas, P. P. Rajendran, P. Krishnan et al., "Extendedspectrum-beta-lactamase producing bacteria related urinary tract infection in renal transplant recipients and effect on allograft function," PLoS One, vol. 9, no. 3, article e91289, 2014.

[4] M. Kashef Nejad, Y. Sharif, and J. N. Hosseini, "Urinary tract infections among kidney transplant patients due to extendedspectrum beta-lactamase-producing bacteria," Microbial Pathogenesis, vol. 107, pp. 276-279, 2017.

[5] J. Abo Basha, M. Kiel, D. Görlich et al., "Phenotypic and genotypic characterization of Escherichia coli causing urinary tract infections in kidney-transplanted patients," Clinical Medicine, vol. 8 , no. 7 , p. $988,2019$.
[6] D. C. Hooper and G. A. Jacoby, "Mechanisms of drug resistance: quinolone resistance," Annals of the New York Academy of Sciences, vol. 1354, no. 1, pp. 12-31, 2015.

[7] I. Korona-Glowniak, K. Skrzypek, R. Siwiec, A. Wrobel, and A. Malm, "Fluoroquinolone-resistance mechanisms and phylogenetic background of clinical Escherichia coli strains isolated in south-east Poland," The New Microbiologica, vol. 39, no. 3, pp. 210-215, 2016.

[8] G. Martín-Gutiérrez, J. Rodríguez-Beltrán, J. M. RodríguezMartínez et al., "Urinary tract physiological conditions promote ciprofloxacin resistance in low-level-quinolone-resistant Escherichia coli," Antimicrobial Agents and Chemotherapy, vol. 60, no. 7, pp. 4252-4258, 2016.

[9] Z. Hashemizadeh, S. Mohebi, D. Kalantar-Neyestanaki, S. Mansouri, H. Hosseini-Nave, and A. Bazargani, "Prevalence of plasmid-mediated quinolone resistance and ESBLs genes in Escherichia coli isolated from urinary tract infections and fecal samples in Southeast Iran," Gene Reports, vol. 17, article 100487, 2019.

[10] S. Sharma, N. Kaur, S. Malhotra, P. Madan, W. Ahmad, and C. Hans, "Serotyping and antimicrobial susceptibility pattern of Escherichia coli isolates from urinary tract infections in pediatric population in a tertiary care hospital," Journal of Pathogens, vol. 2016, Article ID 2548517, 4 pages, 2016.

[11] B. Dormanesh, F. Safarpoor Dehkordi, S. Hosseini et al., "Virulence factors and o-serogroups profiles of uropathogenic Escherichia coli isolated from Iranian pediatric patients," Iranian Red Crescent Medical Journal, vol. 16, no. 2, article e14627, 2014.

[12] M. Halaji, S. Shahidi, A. Atapour, B. Ataei, A. Feizi, and S. A. Havaei, "Characterization of extended-spectrum $\beta$-lactamase-producing uropathogenic Escherichia coli among Iranian kidney transplant patients," Infection and Drug Resistance, vol. 13, pp. 1429-1437, 2020.

[13] P. Wayne, Performance standards for antimicrobial susceptibility testing, Clinical and laboratory standards institute, 2019, Twentynine informational supplement, M100-S29. CLSI 39 (1).

[14] W. P. Chen and T.-T. Kuo, "A simple and rapid method for the preparation of gram-negative bacterial genomic DNA," Nucleic Acids Research, vol. 21, no. 9, p. 2260, 1993.

[15] V. Cattoir, L. Poirel, V. Rotimi, C.-J. Soussy, and P. Nordmann, "Multiplex PCR for detection of plasmidmediated quinolone resistance qnr genes in ESBL-producing Enterobacterial isolates," The Journal of Antimicrobial Chemotherapy, vol. 60, no. 2, pp. 394-397, 2007.

[16] A. Fayyazi, M. Halaji, A. Sadeghi, and S. A. Havaei, "High frequency of integrons and efflux pump in uropathogenic Escherichia coli isolated from Iranian kidney and nonkidney transplant patients," Gene Reports, vol. 21, article 100873, 2020.

[17] M. Giral, G. Pascuariello, G. Karam et al., “Acute graft pyelonephritis and long-term kidney allograft outcome," Kidney International, vol. 61, no. 5, pp. 1880-1886, 2002.

[18] M. Halaji, A. Feizi, A. Mirzaei et al., "The global prevalence of class 1 integron and associated antibiotic resistance inEscherichia colifrom patients with urinary tract infections, a systematic review and meta-analysis," Microbial Drug Resistance, vol. 26, no. 10, pp. 1208-1218, 2020.

[19] S. Khanjani, H. Sedigh Ebrahim-Saraie, Y. Malekzadegan, M. Halaji, and A. Mojtahedi, "Systematic review of antibacterial activity of eravacycline," Reviews in Medical Microbiology, vol. 31, no. 1, pp. 11-16, 2020. 
[20] P. R. Siliano, L. A. Rocha, J. O. Medina-Pestana, and I. P. Heilberg, "The role of host factors and bacterial virulence genes in the development of pyelonephritis caused by Escherichia coli in renal transplant recipients," Clinical Journal of the American Society of Nephrology, vol. 5, no. 7, pp. 1290-1297, 2010.

[21] M. Mohammadzadeh, M. Tavakoli, S. Yaslianifard, E. Asadi, R. Golmohammadi, and R. Mirnejad, "Genetic diversity and antibiotic susceptibility of uropathogenic Escherichia coli isolates from kidney transplant recipients," Infection and Drug Resistance, vol. 12, pp. 1795-1803, 2019.

[22] M. J. Espinar, I. M. Miranda, S. Costa-de-Oliveira, R. Rocha, A. G. Rodrigues, and C. Pina-Vaz, "Urinary tract infections in kidney transplant patients due to Escherichia coli and Klebsiella pneumoniae-producing extended-spectrum $\beta$-lactamases: risk factors and molecular epidemiology," PLoS One, vol. 10, no. 8, 2015.

[23] A. Shapouri Moghaddam, M. Arfaatabar, J. Tavakol Afshari, A. Shakerimoghaddam, Z. Mohammadzamani, and A. Khaledi, "Prevalence and antimicrobial resistance of bacterial uropathogens isolated from Iranian kidney transplant recipients: a systematic review and meta-analysis," Iranian Journal of Public Health, vol. 48, no. 12, pp. 2165-2176, 2019.

[24] M. Shenagari, M. Bakhtiari, A. Mojtahedi, and Z. A. Roushan, "High frequency of mutations in gyrA gene associated with quinolones resistance in uropathogenic Escherichia coli isolates from the north of Iran," Iranian Journal of Basic Medical Sciences, vol. 21, article 1226, 2018.

[25] A. FarajzadehSheikh, H. Veisi, M. Shahin, M. Getso, and A. Farahani, "Frequency of quinolone resistance genes among extended-spectrum $\beta$-lactamase (ESBL)-producing Escherichia coli strains isolated from urinary tract infections," Tropical Medicine \& International Health, vol. 47, no. 1, p. 19, 2019.

[26] Y. Malekzadegan, E. Rastegar, M. Moradi, H. Heidari, and H. Sedigh Ebrahim-Saraie, "Prevalence of quinolone-resistant uropathogenic Escherichia coli in a tertiary care hospital in South Iran," Infection and Drug Resistance, vol. 12, pp. 16831689, 2019.

[27] M. Tarchouna, A. Ferjani, M. Marzouk, I. Guedda, and J. Boukadida, "Prevalence of plasmid-mediated quinolone resistance detrminants among clinical isolates of Escherichia coli in a Tunisian hospitals," International Journal of Current Microbiology and Applied Sciences, vol. 4, pp. 195-206, 2015.

[28] H. Valadbeigi, M. HatamiLak, A. Maleki, E. Kouhsari, and N. Sadeghifard, "Molecular characteristics, antimicrobial resistance profiles, and antibiotic resistance determinants in uropathogenic fluoroquinolone resistant-Escherichia coli isolates," Gene Reports, vol. 18, article 100584, 2020.

[29] M. Röderova, D. Halova, I. Papousek et al., "Characteristics of quinolone resistance in Escherichia coli isolates from humans, animals, and the environment in the Czech Republic," Frontiers in Microbiology, vol. 7, article 2147, 2017.

[30] M. Rezazadeh, H. Baghchesaraei, and A. Peymani, "Plasmidmediated quinolone-resistance (qnr) genes in clinical isolates of Escherichia coli collected from several hospitals of Qazvin and Zanjan Provinces, Iran," Osong Public Health and Research Perspectives, vol. 7, no. 5, pp. 307-312, 2016.

[31] J. P. Nataro and J. B. Kaper, "Diarrheagenic Escherichia coli," Clinical Microbiology Reviews, vol. 11, no. 1, pp. 142-201, 1998.

[32] D. Li, B. Liu, M. Chen et al., "A multiplex PCR method to detect 14 Escherichia coli serogroups associated with urinary tract infections," Journal of Microbiological Methods, vol. 82, no. 1, pp. 71-77, 2010.

[33] S. Yamamoto, "Molecular epidemiology of uropathogenic Escherichia coli," Journal of Infection and Chemotherapy, vol. 13, no. 2, pp. 68-73, 2007.

[34] S. H. Lau, S. Reddy, J. Cheesbrough et al., "Major uropathogenic Escherichia coli strain isolated in the northwest of England identified by multilocus sequence typing," Journal of Clinical Microbiology, vol. 46, no. 3, pp. 1076-1080, 2008.

[35] A. Noie Oskouie, A. Hasani, M. Ahangarzadeh Rezaee, M. H. Soroush Bar Haghi, A. Hasani, and E. Soltani, "A relationship between O-serotype, antibiotic susceptibility and biofilm formation in Uropathogenic Escherichia coli," Microbial Drug Resistance, vol. 25, no. 6, pp. 951-958, 2019.

[36] H. Momtaz, A. Karimian, M. Madani et al., "Uropathogenic Escherichia coli in Iran: serogroup distributions, virulence factors and antimicrobial resistance properties," Annals of Clinical Microbiology and Antimicrobials, vol. 12, no. 1, p. 8, 2013.

[37] S. K. S. Mostafavi, S. Najar-Peerayeh, A. M. Mobarez, and M. K. Parizi, "Serogroup distribution, diversity of exotoxin gene profiles, and phylogenetic grouping of CTX-M-1- producing uropathogenic Escherichia coli," Comparative Immunology, Microbiology and Infectious Diseases, vol. 65, pp. 148-153, 2019. 